Original Research

\title{
Spectrum of Neurological Disorders Encountered at The Neuropediatric Outpatient Clinic at Children's Hospital, Cairo University
}

\author{
Walaa M. El Naggar ${ }^{1}$, Marian Y. Girgis ${ }^{1}$, Hoda M. Abou El Kheir ${ }^{2}$, Mona A. Kamel1* \\ 1 Pediatric Department, Faculty of Medicine, Cairo University, Egypt; \\ marian.girgis@kasralainy.edu.eg, walaa_elnaggar@yahoo.com,dr_monakamel@hotmail.com \\ 2 Ministry of Health, Cairo, Egypt; h.elkhir@yahoo.com \\ * Correspondence: dr_monakamel@hotmail.com \\ Received: 5/11/2020; Accepted: 2/12/2020; Published online: 25/12/2020.
}

\begin{abstract}
:
Background: The various neurological disorders pose a significant proportion of morbidity and mortality among children. They pose significant social and economic challenges as well. Aim of work: To identify the spectrum of neurological disorders among the children attending The Pediatric Neurology Clinic at Children's Hospital, Cairo University.

Methods: Analysis of data of the files of all patients attending the Pediatric Neurology Clinic over a period of 6 months from May 2019 till November 2019. All patients younger than 14 years old were included.

Results: A total of 2819 patients with different neurological disorders were seen during this time interval, their mean (+/- Standard Deviation) age was $9.13+/-7.02$ years with a male predominance $59.9 \%$ vs $40.1 \%$ females. Epilepsy was the most common neurological disorder encountered accounting for about 778 cases $(27.6 \%)$, whereas global developmental delay for differential diagnosis accounted for 480 cases (17.03\%), followed by metabolic disorders (10.7\%) and cerebral palsy (7.24\%).

Conclusion: There is a wide spectrum of childhood neurological disorders among our studied population that demands multidisciplinary team involvement for diagnosis, management and follow up. Our endeavor is challenged by the shortness of professionally trained manpower, as well as limited financial resources for proper access to expensive therapies, all pose great challenge in dealing with patients with neurological disorders in our country.
\end{abstract}

Level of Evidence of Work: III (1).

Keywords: Pediatric Neurological Disorders; epilepsy; spectrum; Egypt; cerebral palsy; children.

\section{Introduction}

Neurological disorders constitute a significant percentage of morbidity and mortality among children and are therefore sources of major concern to parents and health workers worldwide (2). Neurological disorders account for more than $20 \%$ of the world's disease burden with a greater majority of people living in Africa affected. Factors contributing to this increased burden include high incidence of consanguinity, adverse perinatal conditions, meningoencephalitis, and malnutrition (3).

\section{Methods}

This study was conducted at the Pediatric Neurology Clinic at Children's Hospital Cairo University, which opens its door 5 days a week serving an average of 60-80 patients per clinic. Electronic Filing of data of attending children commenced in May 2019. The medical file recorded the detailed clinical data, investigations, and management plans for every child. It is saved electronically on a computerized software system and as a hard copy. At the time of writing this 
article, data of more than 9000 patients following up in the clinic was recorded via the electronic and hard copy filing system of Pediatric Neurology Clinic, Children's Hospital, Cairo University.

\section{Results}

Data of a total of 2819 patients with different neurological disorders were between May 2019 till November 2019 were registered. Their mean (+/- Standard Deviation) age was 9.13 +/-7.02 years with a male predominance $59.9 \%$ vs $40.1 \%$ females. Epilepsy was the commonest neurological disorder encountered accounting for about 778 cases (27.6\%), whereas global developmental delay for differential diagnosis accounted for 480 cases( $17.03 \%)$, followed by metabolic disorders (10.7\%) and cerebral palsy (7.24\%).

Among our studied population, the most common cause of cerebral palsy was hypoxic ischemic encephalopathy (48\%), followed by kernicterus (7\%). The commonest metabolic disorder was phenyl ketonuria (43 cases), followed by mucopolysaccharidosis (42 cases) then organic acidemias (40 cases).

Table 1: Spectrum of neurologic disorders encountered in the Neuropediatric Outpatient Clinic at Children's Hospital, Cairo University between May 2019 till November 2019.

\begin{tabular}{|c|c|c|c|}
\hline Disease & Frequency & Percentage & $\begin{array}{l}\text { Cases per } \\
\quad 1000\end{array}$ \\
\hline Epilepsy & 778 & 27.60 & 275.9 \\
\hline GDD & 408 & 17.03 & 170.2 \\
\hline Metabolic disorders & 303 & 10.75 & 107.4 \\
\hline Cerebral palsy & 204 & 7.24 & 72.3 \\
\hline Intellectual disability & 111 & 3.94 & 39.3 \\
\hline CNS malformations & 101 & 3.58 & 35.8 \\
\hline Muscle dystrophy & 97 & 3.44 & 34.4 \\
\hline Myopathy & 78 & 2.77 & 27.6 \\
\hline Abnormal movements & 52 & 1.84 & 18.4 \\
\hline Stroke & 50 & 1.77 & 17.7 \\
\hline Motor neuron disease & 46 & 1.63 & 16.3 \\
\hline Demyelinating diseases & 42 & 1.49 & 14.8 \\
\hline $\begin{array}{l}\text { Neuromuscular junction } \\
\text { disorders }\end{array}$ & 39 & 1.38 & 13.8 \\
\hline $\begin{array}{l}\text { Pervasive developmental } \\
\text { disorders }\end{array}$ & 33 & 1.17 & 11.7 \\
\hline Neuropathy & 31 & 1.10 & 10.9 \\
\hline Hydrocephalus & 29 & 1.03 & 10.2 \\
\hline Neurocutaneous disorders & 26 & 0.92 & 9.2 \\
\hline Ataxia & 21 & 0.74 & 7.4 \\
\hline Neurodegenerative disorders & 21 & 0.74 & 7.4 \\
\hline Headache & 19 & $0.67 \%$ & 6.7 \\
\hline
\end{tabular}

$\mathrm{GDD}=$ global developmental delay. 
Among cases with CNS malformations, the most common cause was lissencephaly pachygyria complex accounting for $42 \%$. This was followed by agenesis of corpus callosum accounting for $14 \%$. Dandy Walker malformation accounted for $7 \%$, however cerebellar hypoplasia accounted for only $2 \%$ of cases.

Among cases with myopathy, glycogen storage disease was the most common cause and accounted for $32 \%$ of cases, followed by mitochondrial myopathy accounting for $19 \%$ of cases. Furthermore, congenital myopathy was observed in $15 \%$ of cases. On the other hand, among muscle dystrophy cases, Duchenne dystrophy was the most prevalent, and accounted for $60 \%$ of cases.

\section{Discussion:}

Childhood neurology and developmental pediatrics are well-established specialties in highincome countries, where advances in diagnostic techniques have aided the characterization and definition of diseases. The application of recent therapeutic measures has resulted in significantly improved outcome (4).

A big limitation of this study is the short period of observation which was only possible after medical registration was started. However it still gives an idea about the commonest neurological disorders seen in the clinic and its reflection on our community. It also emphasizes which particular diseases need closer attention.

Epidemiological studies show that the prevalence of childhood disabilities is very high. There is a rising incidence of childhood epilepsy, where it reached up to 11.29 per 1000 in Africa (5).

In this study, the prevalence of pediatric epilepsy is found to be very high, about 275 in 1000 with neurologic diseases, hence the need to direct proportionate efforts to diagnose and treat epileptic patients. Challenges of treatment of this cohort of pediatric epilepsy comprises provision of the antiepileptic drugs, constant monitoring to achieve improved child compliance and attention to adverse effects. Furthermore, these large numbers urge conducting more research in the field of epilepsy especially in genetic epilepsies as many of these disorders have a specific treatment. There is a great need to initiate a multidisciplinary team consisting of pediatric neurologists, neuro-radiologists, nutritionists and neurosurgeons to decide the proper lines of treatment for patients with epilepsies, especially intractable epilepsy in order to improve their outcome and reduce the incidence of disability among them.

The high prevalence of cases with global developmental delay without a specific diagnosis is related to the lack of more specialized lab techniques i.e. chromosomal microarray studies that should diagnose most of these cases with genetic origin.

In a low resource country as Egypt, the burden of early diagnosis and follow up of the different metabolic disorders is a great challenge. The newly evolving modalities of therapy of metabolic disorders as bone marrow transplantation, the expensive enzyme replacement and gene therapies are all considered a burden on the economy and compromise their affordability of the health insurance system.

Cerebral palsy was the fourth commonest neurological condition seen. This was similar to the reports from other parts of the world $(6,7)$. Many of the affected children require specialized care and rehabilitative services as well as a multidisciplinary team work. Unfortunately, in our setup and in spite of the high incidence of cerebral palsy, facilities that exist do not provide the adequate care of these patients. The need for well-equipped and affordable rehabilitation centers that might include physical therapy, early intervention programs together with cognitive, behavioral and speech therapies is a mandatory step in improving the quality of lives of such patients. Pediatric neurologic diseases are very demanding. Parental counselling, social and family support of the afflicted child are also in dire need.

\section{Conclusion:}

The Pediatric Neuropediatric Outpatient Clinic at Children's Hospital, Cairo University is a tertiary referral center. The attendees suffered a wide spectrum of childhood neurological disorders. The skilled physicians who serve those children require intensive professional training and continuous professional development. This study underscore the need of skilled professional 
manpower, multidisciplinary team involvement and coordination as well as strategic planning to maximize the financial resources to allow for proper access to expensive investigations and therapies. The limited resources pose great challenge in dealing with patients with neurological disorders in our country.

\section{Author Contributions:}

MYG conceptualized the work; HMA secured data curation; WMN analyzed the data; all the authors searched medical literature, databases, MYG drafted initial manuscript and all reviewed the final manuscript. The authors have read and agreed to the published version of the manuscript.

\section{FUNDING}

The authors declares there was no extramural funding provided for this study.

\section{CONFLICT OF INTEREST}

The authors declares no conflict of interest in connection with the reported study.

\section{References}

1. S. Tenny, M. Varacallo, Evidence Based Medicine. (StatPearls Publishing; Treasure Island (FL), 2020; https://www.ncbi.nlm.nih.gov/books/NBK470182/).

2. T. K. Banerjee, A. Hazra, A. Biswas, J. Ray, T. Roy, D. K. Raut, A. Chaudhuri, S. K. Das, Neurological disorders in children and adolescents. Indian J. Pediatr. 76, 139-146 (2009).

3. J. O. Obi, R. M. Sykes, Neurological diseases as seen at the outpatient Paediatric Neurology Clinic in Benin City. Ann. Trop. Paediatr. 4, 217-220 (1984).

4. I. A. Lagunju, O. O. Okafor, An Analysis of Disorders seen at the Paediatric Neurology Clinic, University College Hospital, Ibadan, Nigeria. West Afr. J. Med. 28 (2009), doi:10.4314/wajm.v28i1.48424.

5. E. Odding, M. E. Roebroeck, H. J. Stam, The epidemiology of cerebral palsy: Incidence, impairments and risk factors. Disabil. Rehabil. 28, 183-191 (2006).

6. R. Duke, C. Torty, K. Nwachukwu, S. Ameh, M. Kim, N. Eneli, A. Onyedikachi, A. Aghaji, K. Burton, L. Dyet, R. Bowman, Clinical features and aetiology of cerebral palsy in children from Cross River State, Nigeria. Arch. Dis. Child. 105, 625-630 (2020).

7. M. Ndiaye, A. Thiam, S. Bagnou, A. K. Ndao, F. Sene-Diouf, A. G. Diop, M. Diagne, M. Ba, M. M. Ndiaye, I. P. Ndiaye, [Cerebral palsy in Dakar]. Dakar Med. 47, 77-80 (2002).

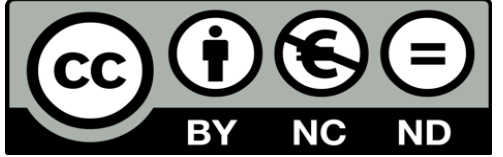

(C) 2020 submitted by the authors. Open access publication under the terms and conditions of the Creative Commons Attribution (CC- BYNC- ND) license. (https://creativecommons.org/licenses/by-nc-nd/2.0/). 